\title{
PRÁTICAS INTEGRATIVAS E COMPLEMENTARES COMO ESTRATÉGIA DE PROMOÇÃO DA SAÚDE DA PESSOA IDOSA
}

Natalia Pereira Araújo; Universidade Regional Integrada do Alto Uruguai e das Missões- Campus de Santiago, RS; nataliaaraujo.uri@gmail.com

Bárbara Belmonte Bedin; Universidade Regional Integrada do Alto Uruguai e das Missões- Campus de Santiago, RS; barbarabbedin@hotmail.com

Diulia Molazzane Gabert; Universidade Regional Integrada do Alto Uruguai e das Missões- Campus de Santiago, RS; diuliagabert@hotmail.com

Letícia dos Santos Balboni; Universidade Regional Integrada do Alto Uruguai e das Missões- Campus de Santiago, RS; s.lbalboni@gmail.com

Patrícia Fonseca Martins; Universidade Regional Integrada do Alto Uruguai e das Missões- Campus de Santiago, RS; patimartins94@gmail.com

Claudete Moreschi; Universidade Regional Integrada do Alto Uruguai e das Missões- Campus de Santiago, RS; clau_moreschi@yahoo.com.br

\section{RESUMO}

Introdução: Com o crescimento da população idosa, os impactos biopsicossociais vivenciados por essa população, podem ser amenizados por meio das Práticas Integrativas e Complementares em Saúde (PICS). Objetivo: Identificar a produção científica existente acerca da utilização das práticas integrativas na promoção da saúde da pessoa idosa. Método: Revisão integrativa da literatura, realizada na Biblioteca Virtual em Saúde, em agosto de 2020, com os descritores "terapias complementares" and "idosos". Foram incluídos artigos na íntegra, disponibilizados online, gratuitamente e em português. $\mathrm{O}$ corpus inicial da pesquisa foi composto de 13 artigos e a amostra foi composta por 3 artigos. Resultados: As três produções analisadas são de abordagem qualitativa, produzidas em periódicos nacionais. Refletiram a seguinte categoria "O uso das PICS na promoção da saúde da pessoa idosa". É necessário o aumento da adesão dos idosos às PICS, uma vez que a mesma proporciona a melhoria da saúde e bem-estar, sendo um desafio para o SUS a implementação da Política Nacional de Práticas Integrativas e Complementares no contexto de vida dos idosos. Há benefícios do uso da reflexologia podal em idosos, para o alívio da insônia, dores corporais e ansiedade. Outra alternativa é a capoterapia, que estimula a inclusão social, a prática de exercícios físicos, diminuição de dores ocasionadas por doenças crônicas, além de conhecimentos sobre o processo de envelhecer. Conclusão: Percebe-se a importância das PICS como aliada na promoção da saúde e envelhecimento saudável da 
população idosa, sendo necessário o planejamento de estratégias que proporcionem a inclusão dos idosos a essas práticas.

Palavras-chave: Terapias Complementares; Idosos; Promoção da Saúde.

\section{Referências}

ALMEIDA, C.A.P.L, SILVA, A.F.F, NETO, L.N.S et al. Capoterapia Como Meio de Inclusão Social para Idosos. Rev Fund Care Online.2019. abr.jun.; 11(3):582-587.

SARAIVA, Alynne Mendonça et al. Histórias de cuidados entre idosos institucionalizados: as práticas integrativas como possibilidades terapêuticas. Revista de Enfermagem da UFSM, v. 5, n. 1, p. 131-140, 2015.

SANTOS et al. Práticas integrativas e complementares: avanços e desafios para a promoção da saúde de idosos. Rev Min Enferm., 22:e-1125, 2018. 